\title{
Multimodality and New Materialism in Science Learning: Exploring Insights from an Introductory Physics Lesson
}

\author{
Delia Marshall \\ https://orcid.org/0000-0003-1799-3478 \\ University of the Western Cape, \\ South Africa \\ dmarshall@uwc.ac.za
}

\author{
Honjiswa Conana \\ https://orcid.org/0000-0002-3573-1239 \\ University of the Western Cape, \\ South Africa \\ cconana@uwc.ac.za
}

\begin{abstract}
Science disciplines are inherently multimodal, involving written and spoken language, bodily gestures, symbols, diagrams, sketches, simulation and mathematical formalism. Studies have shown that explicit multimodal teaching approaches foster enhanced access to science disciplines. We examine multimodal classroom practices in a physics extended curriculum programme (ECP) through the lens of new materialism. As De Freitas and Sinclair note in their book, Mathematics and the Body, there is growing research interest in embodiment in mathematics (and science) education - that is, the role played by students' bodies, in terms of gestures, verbalisation, diagrams and their relation to the physical objects with which they interact. Embodiment can be viewed from a range of theoretical perspectives (for example, cognitive, phenomemological, or social semiotic). However, they argue that their new materialist approach, which they term "inclusive materialism", has the potential for framing more socially just pedagogies. In this article, we discuss a multimodal and new materialist analysis of a lesson vignette from a first-year extended curriculum physics course. The analysis illuminates how an assemblage of bodily-paced steps-gestures-diagrams becomes entangled with mathematical concepts. Here, concepts arise through the interplay of modes of diagrams, gestures and bodily movements. The article explores how multimodal and new materialist perspectives might contribute to reconfiguring pedagogical practices in extended curriculum programmes in physics and mathematics.
\end{abstract}

Keywords: new materialism; multimodal; physics; mathematics; extended curriculum programme

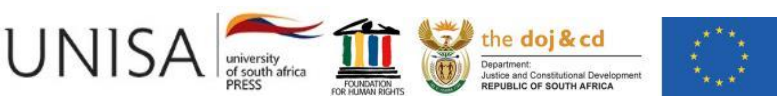

Education as Change

https://upjournals.co.za/index.php/EAC

Volume 25 | 2021 |\#8848 | 18 pages

https://doi.org/10.25159/1947-9417/8848 ISSN 1947-9417 (Online)

(C) The Author(s) 2021 


\section{Introduction}

Issues of access and retention in STEM (science, technology, engineering and mathematics) disciplines are areas of concern, with global trends indicating declining enrolments and high attrition in these disciplines (see, for example, Chen and Soldner 2013; OECD 2008). In South Africa, STEM fields show high attrition at first-year level, and low overall completion rates; furthermore, student participation and success in these fields remain racially skewed (Council on Higher Education [CHE] 2013). To address these access and equity concerns, foundational or extended curriculum programmes (ECPs), designed to enable access to university for school-leavers underprepared for undergraduate studies, were introduced in South African universities. Drawing on Moje's (2007) notion of socially just pedagogy (that is, pedagogy that provides equitable opportunities for all students to engage with learning), science ECP programmes can be viewed as framed by socially just pedagogies, since the focus is inducting students traditionally marginalised from science studies into the valued disciplinary knowledge of the sciences. Unequal access to higher education in South Africa was highlighted in the 2015 student protests calling for the scrapping of university fees (under the banner \#FeesMustFall) and for the decolonisation of university curricula (Jansen 2019). A smaller, but related, \#ScienceMustFall movement called for decolonising the STEM curricula; this call was closely linked to concerns about how to make undergraduate science more accessible to all (Airey and Simpson 2019).

This article examines multimodal and new materialist perspectives in the context of widening access to undergraduate science and mathematics studies. We explore the insights that these perspectives might offer to issues of access and inclusion in these areas. In the first part of this article, we present a brief overview of new materialism and the "inclusive materialism", introduced by De Freitas and Sinclair (2014), which builds on the work of physicist-philosopher Karen Barad and the philosopher Gilles Châtelet. We then discuss new materialism in the context of undergraduate STEM education, especially the role of embodiment in learning, and we review similar work from physics education on embodiment from a multimodality perspective (Hwang and Roth 2011). In the next section of the article, we present an analysis of an ECP physics lesson vignette to explore one of the key themes in this special edition: How might multimodal and new materialist perspectives contribute to socially just pedagogies and making knowledge more accessible in extended curriculum programmes?

\section{New Materialism and "Inclusive Materialism"}

New materialist approaches argue for a "material turn" in philosophy and social theory (for example, Barad 2007; Haraway 2008). These approaches emphasise the entanglement of material and discursive realities, human-nonhuman encounters, and engagements with matter. An important concept of new materialist perspectives is the notion of relational ontology, an ongoing process in which matter and meaning are coconstituted. In new materialism, material-discursive phenomena, matter and meaning 
are seen as entangled. Karen Barad, a key new materialist proponent, is a physicist and feminist philosopher, and explores the ontological implications of quantum physics in her book, Meeting the Universe Halfway: Quantum Physics and the Entanglement of Matter and Meaning (2007). Barad draws on the work of Niels Bohr and his writings on the implications of quantum physics. Bohr argues quantum physics implies that objects do not have their own fixed properties, but that the process of measurement affects these properties.

Barad uses the implications of quantum physics to challenge the traditional subject/object divide. This suggests that there are no clear boundaries between subject and object, or the social and material. Barad argues that entities exist only in their "intraactions". The term "intra-action", coined by Barad (2007), is a concept that emphasises how bodies and discourses are co-implicated and relational. Intra-action assumes that entities or bodies are relational: they come into being through their relationship. This is in contrast to the commonplace notion of interaction, which presumes the prior existence of independent entities/agencies. Barad refers to the entanglement of matter and meaning.

In the context of mathematics learning, De Freitas and Sinclair, in their book Mathematics and the Body (2014), build on Barad's work to explore the entanglement of matter and mathematical concepts. They challenge the dominant view of mathematics as "an abstract, static discipline that resists any links with the physical world" (De Freitas and Sinclair 2014, 1). They argue that mathematics as a discipline is strongly connected to the physical world. This has implications for their perspective on mathematics learning: they challenge the traditional perspective of mathematics learning as "acquiring mathematical concepts", with its implicit Cartesian mind-body divide. Instead, they show how concepts come into being through a material assemblage ${ }^{1}$ of learning.

De Freitas and Sinclair develop the notion of "inclusive materialism" in relation to learning mathematics. They argue that their "theory of matter ... resists the binary divide between human agency and inert passive matter" $(2014,39)$. They note how a relational ontology allows for a reframing of the commonplace view of learning as comprising "a discrete, independent body that simply interacts with mathematical concepts" (2014, 50). As Rotman notes in the foreword to their book, their "inclusive materialist" approach "includes and foregrounds the activity of the body, against the longstanding mentalist conception of mathematics as an activity of pure, abstract thought" (2014, xx).

In challenging this dominant mentalist conception of mathematics as abstract, disembodied thought, De Freitas and Sinclair draw on Châtelet's book, Figuring Space (2009), which provides a rich and fascinating historical look at how mathematics as a discipline developed. As De Freitas and Sinclair note, "[w]e saw in Châtelet a way of

Assemblage is a notion they draw from Deleuze and Guattari (1987), meaning an emergent unity joining together heterogeneous entities. 
better understanding how materiality might matter for mathematics, which has for so long been taken as an abstract and static discipline that resists any links with the physical world" (De Freitas and Sinclair 2014, 1).

Châtelet presents historical case studies to show that gesture and diagrams have in fact been key to the development of mathematical ideas and demonstrates vividly that even very abstract mathematical constructs have their origins in the material realm. His case studies also illustrate that diagrams and gestures serve as more than mere illustrations or representations of existing mathematical concepts and are instead "material events that ... bring new mathematical meanings into being" (Rotman 2014, x). In foregrounding the central role of diagrams and gestures in the historical development of mathematics, Châtelet's case studies challenge the Kantian mind-body divide that is still dominant in mathematics.

Châtelet also puts forward the idea of "virtuality" and conceives of mathematical entities as material objects possessing both virtual and actual dimensions. The "virtual" is the link between the mathematical and the physical world. Developing this idea, De Freitas and Sinclair argue for the need to view the actual (for example, entities such as diagrams, geometric shapes, or numbers) "less as static figures and more in terms of the virtual motions that they generate" $(2014,205)$. They note that this mobility is central to the concept of virtuality and allows the imagination of new possibilities and configurations.

Extending their focus from Châtelet's historical studies to contemporary mathematics, Sinclair and Gol Tabaghi (2010) draw on their research on the mathematical understanding of contemporary mathematicians. They found that, despite the formal, written formalism of mathematics, language and gesture were central in how these mathematicians conveyed mathematical meaning.

In summary, De Freitas and Sinclair argue that the new materialist emphasis on the body counters the commonplace mentalist conception of mathematics as comprising abstract, rarefied thought. This mentalist conception of mathematics can be experienced as exclusionary to students; in contrast, their "inclusive materialist" approach that "includes and foregrounds the activity of the body" (Rotman 2014, xx) can make mathematical knowledge more accessible.

\section{New Materialism and STEM Education}

In the field of mathematics education research, there is growing interest in embodiment in mathematics education - that is, the role played by students' bodies in terms of gestures, verbalisation, diagrams and their relation to the physical objects with which they interact. From an embodied cognition perspective (Lakoff and Núñez 2000), abstract mathematical understanding is seen to emerge out of concrete sensory motor experiences, although in this perspective the social aspect of learning is not foregrounded. As De Freitas and Sinclair argue, embodiment in mathematics education 
is viewed from a range of theoretical perspectives, but much of this work assumes the mind-body divide and "conceives of diagrams and gestures as 'external' representations of abstract mathematical concepts or cognitive schemas" (De Freitas and Sinclair 2012, 134).

For example, sociocultural perspectives on learning are interested in how students access a disciplinary discourse and how students enact identity through discourse. De Freitas and Sinclair note that, while they are sympathetic to the sociocultural perspectives in mathematics education (for example, Sfard 2008), these perspectives do not take the body sufficiently into account.

Similarly, they note that the "linguistic turn" in education research has produced useful research on the role of language in mathematics and science classrooms, for example, how particular grammatical structures of mathematics and science (for example, nominalisations, dense noun phrases, third person, passive voice) can hinder learning and portray mathematics and science as objective and dehumanised (see, for example, Lemke 1990; O'Halloran 2005). In a similar vein, Martin (2007) argues that the formal grammar of written mathematics, in contrast to the less formal spoken mathematics of the classroom, "is possibly what makes it such a gate-keeping discipline" (Martin 2007 cited in De Freitas and Sinclair 2014, 113).

However, despite the usefulness of the sociolinguistic perspective in understanding the role of language in learning mathematics, De Freitas and Sinclair note that this perspective retains the Kantian body-mind divide. Spoken words are conceptualised as "carriers of otherwise disembodied meanings" $(2014,117)$. Gesture and diagrams are viewed as representations or illustrations of concepts, rather than integral to the creation of meaning, and speech is viewed as translating thought. This shores up the view of mathematical concepts as disembodied, abstract thought. Associated with this mental, disembodied view of mathematics is the idea that "mathematical intuition" and "innate ability" are required for success in mathematics. This has important implications for STEM teaching because many students and their teachers believe that "some people are born with a 'math brain' and some are not, and that high achievement is only available to some students" (Boaler et al. 2018, 1).

Working in the context of undergraduate physics, Hwang and Roth (2011) view learning from a material phenomenology perspective. They are similarly critical of sociocultural and linguistic perspectives, arguing that these equate thought with language and downplay the role of the body in learning. In their study of the role of multimodality in physics lectures, they show that concepts are best thought of as arising from the interrelations of different modalities, including gestures, body movements, body positions and voice intonation. Here, modes of gesture and body movements are not merely representations or illustrations of concepts - instead meaning arises through them. 


\section{Multimodality and Social Semiotics in Physics Learning}

Science disciplines are inherently multimodal, with scientific ideas inscribed in various modes-mathematical, diagrams, pictures, tables, graphs, gestures as well as written/verbal language. Meaning-making arises in the interplay between these modes. Newfield (2014) notes that shifting or translating from one modal form to another (what she terms "transmodality") constitutes learning. Science teaching, then, is also inevitably multimodal, with teachers using action, gesture, speech, writing, image and role play to communicate scientific knowledge. Kress et al. (2001) refer to these as comprising "a multimodal ensemble" $(2001,1)$. However, they note that speech and writing have traditionally been the dominant modes in the science classroom, with other modes (such as gesture and action) "generally considered illustrative supports to the 'real thing"' (2001, 51). With resonances of new materialism, multimodal research foregrounds the role of materiality as a semiotic resource: "the concrete material 'stuff' used in communicating the matter of science education cannot be ignored. The materials, chemicals, apparatus and models are imbued with meaning" (Kress et al. 2001, 11).

A multimodal social semiotics perspective to science teaching and learning considers the language of science a cultural tool for meaning-making, where the mode used to inscribe the scientific ideas produces the intended meanings for the meaning-maker (Kress et al. 2001). Within the field of physics education, social semiotics perspectives have productively been used to examine student learning. Here, physics learning is viewed as "becoming fluent in a critical constellation" of modes (Airey and Linder 2009, 27). Each mode (speech, graph, diagram, mathematics, gesture) can be seen to have different affordances, and meaning-making can be viewed as the effect of all these modes acting jointly. Volkwyn et al. (2019), drawing on Bezemer and Kress (2008), describe the movement from one mode to another as "transduction". Studies show that a multimodal conceptualisation of science teaching enables students to better access the semiotic resources needed for successful learning of science (Airey and Simpson 2019).

As Airey and Linder (2017) note, the social semiotics perspective deviates from the more traditional cognitivist lens used to understand the role of multiple representations in science education. Studies have been conducted in physics education on the role of representations in teaching and learning physics (for example, Rosengrant, Van Heuvelen, and Etkina 2009; Van Heuvelen 1991) and on how students develop representational competence (for example, Kohl and Finkelstein 2008). These studies on representations in physics have yielded many valuable insights. However, they differ in a few important respects from a social semiotics or new materialist perspective. The main difference is that the representations research views multiple representations as illustrating a concept, whereas a social semiotics perspective takes a nonrepresentationalist perspective. In this perspective, meaning is not represented but concepts come into being through gesture, diagram, and speech. Another difference is 
that there are semiotic resources used in physics that tend not to be classified as representations, such a physical objects (for example, apparatus) and actions.

Hwang and Roth (2011) note that the representationalist perspective is common in physics education, where different modes are seen as equivalent. They note that the representationalist perspective does not adequately account for the role of embodiment in physics learning. Their study of university physics lectures shows that there is a privileging of texts and words, with the assumption that "embodied aspects of communication other than words (e.g., gesture, body orientation) are supplementary such that their sense can be articulated by means of words" (Hwang and Roth 2011, 40). Implicit in the representationalist perspective is that modes such as gesture and diagrams are viewed as representations or illustrations, rather than key to the creation of meaning.

In summary, what is common to both social semiotics and new materialism is their nonrepresentationalist perspective: gestures and diagrams are not illustrative of concepts, but rather concepts emerge from them. As De Freitas and Sinclair note: "Diagrams are more than depictions or pictures or metaphors, more than representations of existing knowledge: they are kinematic capturing devices" (De Freitas and Sinclair 2014, 65).

\section{A New Materialist Analysis of an ECP Lesson Vignette}

This section presents an analysis of a lesson vignette from an extended curriculum programme (ECP) physics course. The multimodal aspects of the teaching are examined through the lens of new materialism. The lesson was video-recorded, and the multimodal aspects (audio, gestures, diagrams) were transcribed and analysed.

As noted earlier, ECPs were introduced in South African universities to enable access to university for students underprepared for undergraduate studies, many of whom are first generation in higher education. The extended Bachelor of Science (BSc) curriculum programme extends a three-year BSc degree over four years, allowing more time and curriculum space in the first two years of the degree for addressing foundation aspects, such as conceptual understanding, mathematical and academic literacy skills. At the time of this research study, one of the authors of this article (Conana) was working as an academic development specialist in the physics extended curriculum programme; the other author (Marshall) was a lecturer in this department, though not involved directly in the extended curriculum programme.

This ECP lesson was selected since it was an introduction to the section on linear motion, intended to explore students' prior understandings of vectors and co-ordinate systems. Since many of the students in the ECP come to university with conceptual gaps in their physics knowledge from high school, building a firm conceptual foundation at the outset is important.

As a prelude to this lesson vignette, we first set out the key mathematical and physics concepts in the lesson. Vectors are mathematical quantities that have a magnitude (or 
length) and a direction. Physics takes place in three-dimensional space where many fundamental quantities are represented by vectors. Vectors provide the mathematical framework needed for the study of mechanics (the area of physics dealing with the study of motion and causes of motion). Many of the entities describing motion and its causes are vectors, for example, displacement, velocity, force and momentum. Further on in their studies, students will also encounter the rotational counterparts of these entities (for example, angular velocity, torque, angular momentum), which are also vector quantities.

A key tool in working with vectors is the fundamental notion of a co-ordinate system. This consists of an origin, along with two (or three) mutually perpendicular axes. A key feature of a co-ordinate system is that its origin and orientation in space are movable, and "it is this movability that allows the simplification of many complicated forms of physics modelling and application" (Volkwyn et al. 2017, 409).

A formal abstract definition of a position vector in an introductory mathematics or physics textbook would look something like this:

A position vector is a Euclidean vector that represents the position of a point $\mathrm{P}$ in space in relation to an arbitrary reference origin $\mathrm{O}$. It corresponds to the straight line segment from $\mathrm{O}$ to $\mathrm{P}$. In other words, it is the displacement or translation that maps the origin to $\mathrm{P}$.

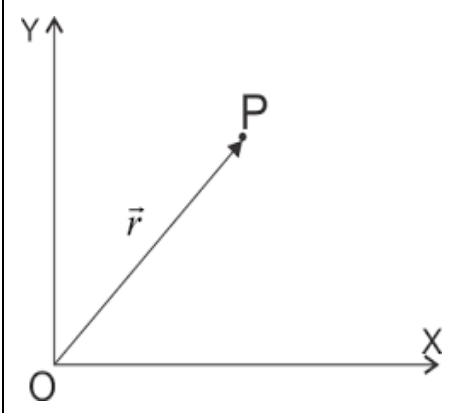

Figure 1: Common textbook definition of a "position vector"

The lesson observed was an introduction to linear motion. The lecturer started the lesson with a class discussion on how motion might be described. He asked the students: "Name any physical quantities that can describe motion", and as students called out a range of physics terms, he wrote these on the board: speed, velocity, position, distance, displacement, acceleration, time. The lecturer then posed the question: "Which of these are vector quantities?" (that is, having both magnitude and direction). Students discussed in small groups, and lively conversations with much gesticulating ensued. The students then voted on whether each of these concepts is a vector or not. Students identified displacement, velocity and acceleration as vector quantities, and it became evident that the majority of the students were unsure whether "position" is a vector or 
not. Some noted that concepts such as velocity and acceleration describe motion, and therefore must have a direction; "position", on the other hand, seemed to the students to be static, and therefore possessing no particular direction.

To address this difficulty, the lecturer then designed a class activity: students were told that they need to direct a blindfolded peer from an initial position to a final position in the classroom, taking the classroom door as a reference point. The lecturer stood at the door and indicated the initial position (a point in front of the row of desks), and then pointed to the final position (on the other side of the classroom) where the student should end up (see the sketch in Figure 2).

The students worked on this task in groups of four. The working of a single group is described here. The students decided which peer would be blindfolded. They then realised that they needed to measure his pace-length and so they asked him to walk five paces while they measured - with a metre stick - the distance he covered. The students counted in unison, "one, two, three, four, five ..." and then "stop". The student remained stationary while another student measured the distance travelled and worked out the size of his paces. In this way, his steps were calibrated, as he would be part of the measuring apparatus. The student was then asked to sit out, so that he would not overhear their discussions about the route he would be instructed to take.

The students planned the route from the initial position to the final position, taking into account how the fixed desks constrain the possible pathways. They drew a sketch of the classroom and the route to be taken.

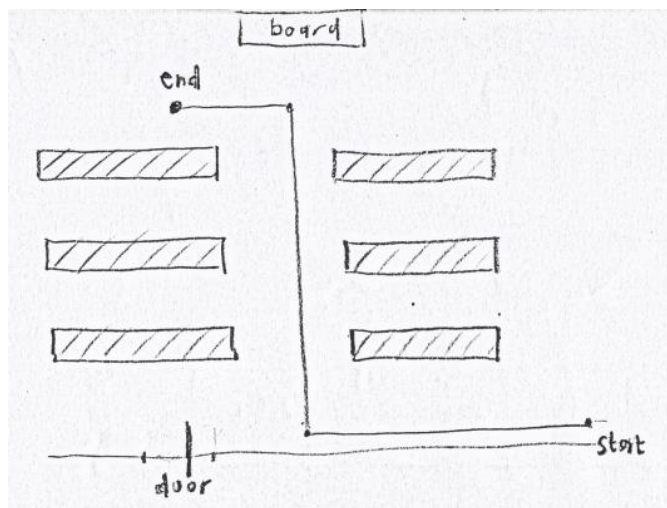

Figure 2: Student's sketch of a route along which to direct a blindfolded student

The students discussed how they would name directions, gesturing with their arms "left, right, forwards, backwards". They stood at the door (the reference point) and paced out the distance from the door to the starting point (10 steps away). Here, the meaning of a "co-ordinate system" comes into being through the embodied activity ("Where am I relative to the door, and in which direction?"). As they paced out the distance from the reference point (the door) to the starting point, they counted: "One, two three, four ...". 
They then paced the distance to each point on the route they had designed. They drew more sketches and wrote the instructions in words. Then, they called over their peer to be blindfolded, and tried out their written instructions with him, guiding him through verbal instructions from the starting point to the end point.

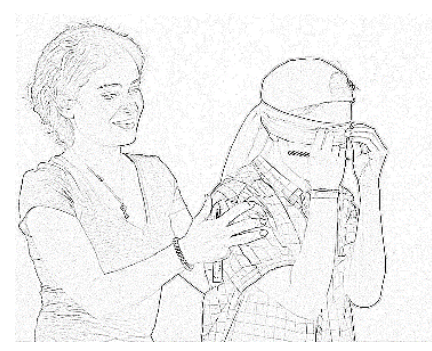

Figure 3: A student prepares to direct a blindfolded fellow student

Once the groups had all tried out their instruction on their blindfolded peers, the lecturer asked for feedback, and one group volunteered to share their route. There was a class discussion about how to represent this route, and the reference point (the door) was taken to be the origin on a co-ordinate system. The students translated their instructions, "forwards, left, right", onto the co-ordinate system: "We will take towards the front of the classroom as in the positive y-direction, and to the right as in the positive $\mathrm{x}$ direction". As they discussed their choice, they realised that another group may have chosen a different orientation for the co-ordinate system. Here, they experienced how the orientation of a co-ordinate system is movable in space. At this point in the lesson, we observe how the assemblage of bodily-paced steps-gestures-diagrams becomes entangled with mathematical concepts. The meaning of a co-ordinate system is created through the embodied activity ("How will we describe directions? Where am I relative to the door, and in which direction?"), not merely illustrated in a sketch. First-year physics students often do not see the relevance of a co-ordinate system; in this activity, they experienced this usefulness in a very embodied way.

The lecturer then moved from the bodily enactment of the position vector (moving from the door to the starting position, 10 steps away) to the drawing of the position vector $\vec{r}_{0}$ on the co-ordinate system (with " 0 " indicating the starting position). 


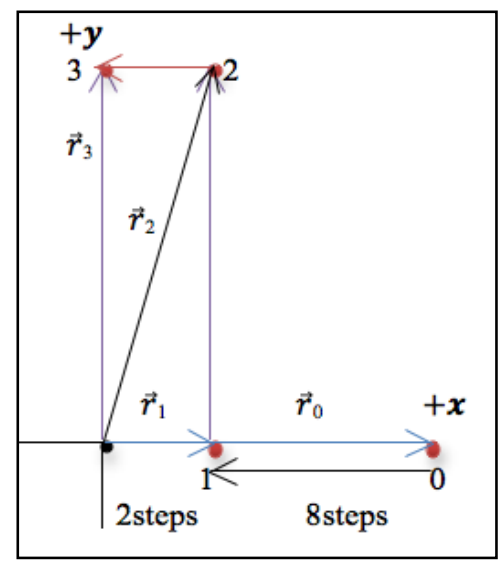

Figure 4: Co-ordinate system with position vectors $\overrightarrow{\boldsymbol{r}}_{0}, \overrightarrow{\boldsymbol{r}}_{1}, \overrightarrow{\boldsymbol{r}}_{2}$ and $\overrightarrow{\boldsymbol{r}}_{3}$

The lecturer explicitly unpacked aspects of the diagrammatic mode. He explained:

The vector as an arrow has an important information. ... The line segment has half of the information about the vector, in other words, the magnitude only. The head of the arrow shows the direction of the vector. Therefore, it is important for you to communicate properly. ... Start developing a habit of labelling vectors correctly. This is how physics communicates.

Through class discussion about the route taken by the lecturer (from the starting position, labelled " 0 ", to the end position, labelled " 3 " in Figure 4), the other position vectors are also drawn on the co-ordinate system and labelled $\vec{r}_{1}, \vec{r}_{2}, \vec{r}_{3}$. The meaning of the symbolic form of the position vector $\vec{r}_{0}$ and $\vec{r}_{1}$ emerges through the embodied movement - the arrow on the top of $\vec{r}_{1}$ indicates that movement from the door to position 1 was in a particular direction. "Position as a vector" is felt in the students' bodies. This embodied experience of position as a vector is then related to the diagram. The lecturer linked the material object - the door-to the origin of the co-ordinate system, explaining that: "Position vectors describe how far you are relative to the origin [pointing at the diagram to explain this], at position $0,1,2$, and 3 . That is what the subscript in $\overrightarrow{\mathrm{r}}_{0}, \overrightarrow{\mathrm{r}}_{1}, \overrightarrow{\mathrm{r}}_{2}$ is indicating."

Once the vector quality of "position vector" had been experienced by the students, the lesson moved to the meaning of "displacement vector" as the difference between the final and initial position vectors. The lecturer followed the instruction of the group, walking eight steps from position 0 to position 1 . He then drew the displacement vector on the co-ordinate system, depicted by an arrow starting at position 0 and ending at position 1 (see Figure 5a). He then shifted from the vector diagram to writing this displacement vector in its dense symbolic form (see Figure 5b). 


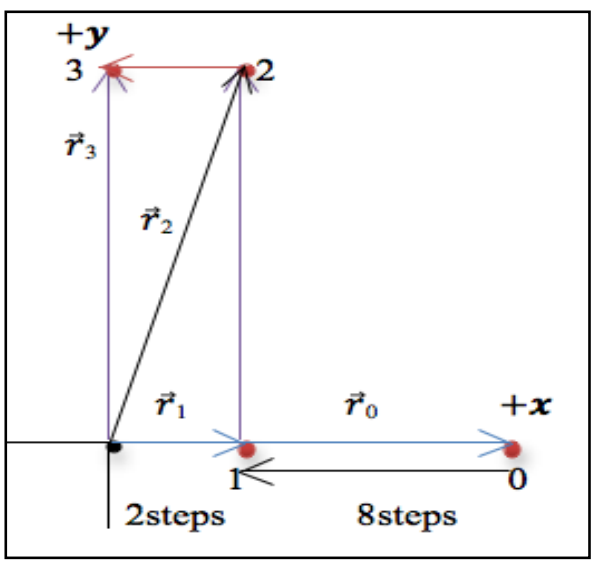

$$
\begin{aligned}
& \Delta \vec{r}_{01}=\vec{r}_{1}-\vec{r}_{0} \\
& =(2 \text { steps },+x)-(10 \text { steps },+x) \\
& =-(8 \text { steps },+x) \\
& =-8 \text { steps, }+x \\
& \text { OR } \\
& =8 \text { steps },-x \\
& \therefore \Delta \vec{r}_{01}=8 \text { steps, }-x \text { direction }
\end{aligned}
$$

Figure 5a: Co-ordinate system with “displacement vector” drawn; Figure 5b: "Displacement vector" in symbolic form

As with "position as a vector", the meaning of "displacement vector" emerges through embodied movement. The symbolic format $\Delta \mathrm{r}_{01}$ of the displacement vector becomes entangled with the embodied movement of the students: the ' $\Delta^{\prime}$ and the subscript " 01 " are felt as the change in position, moving from position 0 to position 1.

The lecturer related the concept of the displacement vector and its symbolic representation $\left(\Delta \vec{r}_{01}=\vec{r}_{1}-\vec{r}_{0}\right)$ back to the concrete blindfold activity, with $\vec{r}_{1}$ and $\vec{r}_{0}$ being related to the steps taken by the students from the origin (the door).

In this ECP lesson vignette, we can see multimodal teaching at play: verbal descriptions are translated into gestures and sketches, then explicitly converted to vector diagrams. The vector construct is carefully unpacked (the meaning of the vector arrow and length), and then the displacement vector (as the difference between two position vectors) is explicitly written in symbolic form. Here, we see a "transmodal" series of shifts or "chains of semiosis" from one modal form to another (Newfield 2014) or what is also termed "transduction" between modes (Volkwyn et al. 2019).

The role of gesture and embodiment were also highlighted. Concepts such as "position vector" were not so much illustrated in the blindfold activity as coming into being through the activity. We observe how the assemblage of bodily-paced steps-gesturesdiagrams becomes entangled with mathematical concepts. The meaning of a co-ordinate system is created through the embodied activity ("How will we describe directions? Where am I relative to the door, and in which direction?"), not merely illustrated in a sketch. Discussion on how to place and orient the co-ordinate system opens up the concept of the "virtual" - the mobility inherent in the co-ordinate system allowing many other potential orientations, configurations and vector diagrams.

Before the blindfold activity, many students thought of position as a scalar quantity. But through bodily pacing, being "10 steps from the door", the new concept of "position 
as vector" comes into being. Students experienced bodily that position is specified in terms of a direction from a point of reference. Similarly, speech and rhythm played a central role: as the students paced out the distance from the reference point (the door), the counting and the physical pacing coincided: "One, two three, four ...". Here, speech is not just a conveyer/representation of thought; instead, meaning is created through the rhythm of counting, and the counted steps become the units of the position vector.

In this series of activities, we observe how new mathematical meaning comes into being through the assemblage of bodily-paced steps-gestures-diagrams-dense symbolic text. We see echoes of this in the work of De Freitas and Sinclair (2014) on the number line, where the body of the number line engages with the body of the student, and a new kind of body-assemblage comes into being.

\section{Discussion}

We undertook this investigation of an ECP lesson vignette through the lens of new materialism to explore one of the key themes in this special edition: How might multimodal and new materialist perspectives contribute to socially just pedagogies and making knowledge more accessible in extended curriculum programmes?

Our previous research had been located in a representationalist perspective, examining how physics students develop representational competence (Conana, Marshall, and Case 2020). This perspective has proved productive in mapping how representations are explicitly unpacked in classroom teaching. This is particularly useful for making knowledge more accessible to students, since research shows that representations are often taken for granted in teaching (see, for example, Dufresne, Gerace, and Leonard 1997; Fredlund, Airey, and Linder 2012). This approach was also useful in examining how students move between representations and develop "metarepresentational competence" (Kohl and Finkelstein 2008).

However, we recognised that the representational perspective maintains a dualist perspective and does not sufficiently take into account the role of embodiment in learning. For this reason, we were interested to explore the usefulness of a new materialist perspective, drawing as it does on the non-dualist ontological implications of quantum physics (Barad 2007). We were particularly interested in De Freitas and Sinclair's notion of "inclusive materialism", which seemed a potentially generative framework with which to think about ECP teaching.

In the following section, we discuss what emerged from this analysis and explore how multimodality and new materialism might contribute to reconfiguring pedagogical practices in undergraduate physics and mathematics. There were several key insights that emerged.

First, the relational ontology of new materialism challenges the Kantian mind-body divide that is dominant in STEM disciplines. In mathematics, in particular, the view of 
mathematical concepts as disembodied, abstract thought is commonplace. Associated with this mental, disembodied view of mathematics is the idea that "mathematical intuition" and "innate ability" are required for success in mathematics. This has important implications for STEM teaching, because many students and their teachers believe that "some people are born with a 'math brain' and some are not, and that high achievement is only available to some students" (Boaler et al. 2018, 1). This belief in innate ability is also linked to the widespread phenomenon of "mathematics anxiety", which undermines confidence and motivation of students (Ashcraft 2002; Ma 1999). Therefore, decentring the mentalist notion of "innateness" is important for challenging exclusionary perspectives of mathematics and widening access to mathematics as a discipline. ${ }^{2}$ The "inclusive materialist" approach (De Freitas and Sinclair 2014) that foregrounds the role of the body in learning has the potential to make mathematics learning more accessible.

Second, the new materialist literature, drawing on historical and philosophical developments in STEM disciplines (for example, Barad in physics and De Freitas and Sinclair in mathematics), points to the potential of these historical and philosophical perspectives for undergraduate teaching. As De Freitas and Sinclair (2014) argue, the relational ontology of new materialism is supported by Châtelet's historical case studies of how mathematics as a discipline evolved. These case studies indicate that gesture and diagrams were not used to represent or illustrate new mathematical ideas, but were central to their coming into being. The implications for undergraduate teaching might be to include historical accounts of the STEM disciplines, and to discuss the central role of diagram and gesture in the historical development of the disciplines as well as contemporary work (for example, Sinclair and Gol Tabaghi 2010).

Third, the new materialist approach provides an alternative to the representationalist perspective dominant in many theoretical perspectives in mathematics and physics educational research. Many of these perspectives view diagrams, gestures, and language as representations of concepts already "in the head". They are seen to perform an ancillary, add-on role in learning. In contrast, a new materialist framework views diagrams, gestures, and language not merely as illustrations or representations of an abstract concept, but rather proposes that these bring the concept into being. In the lesson presented in this article, the analysis revealed how the assemblage of bodilypaced steps-gestures-sketches-vector diagrams becomes entangled with the mathematical concepts. The concepts of position vector and displacement vector emerge through the embodied activities.

This non-representationalist perspective has fruitful implications for STEM teaching. Mathematics, in particular, with its strong mentalist framing, tends to be taught in an

2 In the South African context, apartheid education deliberately limited access to mathematics education to black learners, with the rationale that they would not need such abstract thinking in their working lives. Here, we also see resonances of colonial rationality, and the racism in Kant's mind-body dualism, with his framing of rationality as "not-Black" (Harfouch 2018). 
abstract way, with little focus on gesture or the body. As De Freitas and Sinclair (2014) note, in mathematics, "ability is ascribed to some sort of internal intuition or mental faculty. Such an approach looks suspiciously at material assemblages of hand, eye, paper, concept" (De Freitas and Sinclair 2014, 158-59). Similarly, physics education research shows that written modes dominate. Hwang and Roth (2011) argue that in university physics lectures there is a privileging of texts and words, with the assumption that "embodied aspects of communication other than words (for example, gesture, body orientation) are supplementary such that their sense can be articulated by means of words" (Hwang and Roth 2011, 42).

In summary, what are the implications of multimodal and new materialist perspectives for reconfiguring pedagogical practices in extended curriculum programmes in physics and mathematics? The "inclusive materialism" of new materialism (with its foregrounding of the body) is useful in countering the mentalist conceptions of mathematics as "an activity of pure, abstract thought" (Rotman 2014, xx) and the notion of mathematical ability as "innate". This foregrounding of the body has the potential to make mathematics learning more inclusive. Extended curriculum programmes have the extra time and curriculum space to explore and experiment with the role of embodiment in teaching and learning. The non-representationalist perspectives of new materialism and multimodality highlight the benefits of a greater focus on gesture and the body in the learning of mathematics and physics, not merely as ancillary or supplementary "addons" but as integral to the creation of meaning. Finally, the lesson vignette analysis opened up new questions for future enquiry, in particular, the role of the virtual in physics co-ordinate systems, and how the virtual motion or mobility in the actual (for example, physics diagrams) can be harnessed in the exploration of new teaching and learning possibilities.

\section{References}

Airey, J., and C. Linder. 2009. “A Disciplinary Discourse Perspective on University Science Learning: Achieving Fluency in a Critical Constellation of Modes". Journal of Research in Science Teaching 46 (1): 27-49. https://doi.org/10.1002/tea.20265.

Airey, J., and C. Linder 2017. "Social Semiotics in University Physics Education”. In Multiple Representations in Physics Education, edited by D. Treagust, R. Duit, and H. Fischer, 95122. Cham: Springer. https://doi.org/10.1007/978-3-319-58914-5_5.

Airey, J., and Z. Simpson. 2019. "Increasing Access to Science and Engineering-The Role of Multimodality”. Designs for Learning 11 (1): 138-40. https://doi.org/10.16993/dfl.144.

Ashcraft, M. 2002. "Math Anxiety: Personal, Educational, and Cognitive Consequences". Current Directions in Psychological Science 11 (5): 181-85. https://doi.org/10.1111/14678721.00196. 
Barad, K. 2007. Meeting the Universe Halfway: Quantum Physics and the Entanglement of Matter and Meaning. Durham, NC: Duke University Press.

https://doi.org/10.2307/j.ctv12101zq.

Bezemer, J., and G. Kress. 2008. "Writing in Multimodal Texts: A Social Semiotic Account of Designs for Learning”. Written Communication 25 (2): 166-95. https://doi.org/10.1177/0741088307313177.

Boaler, J., J. A. Dieckmann, G. Pérez-Núñez, K. L. Sun, and C. Williams. 2018. “Changing Students Minds and Achievement in Mathematics: The Impact of a Free Online Student Course". Frontiers in Education 3: 1-7. https://doi.org/10.3389/feduc.2018.00026.

Châtelet, G. 2009. Figuring Space: Philosophy, Mathematics and Physics. New York, NY: Springer.

Chen, X., and M. Soldner. 2013. STEM Attrition: College Students' Path into and out of STEM Fields: Statistical Analysis Report. Washington, DC: US Department of Education. Accessed December 11, 2021. http://nces.ed.gov/pubs2014/2014001rev.pdf.

CHE (Council on Higher Education). 2013. A Proposal for Undergraduate Curriculum Reform in South Africa: The Case for a Flexible Curriculum Structure. Report of the Task Team on Undergraduate Curriculum Structure. Pretoria: CHE. Accessed December 11, 2021. https://www.che.ac.za/node/16156.

Conana, H., D. Marshall, and J. M. Case. 2020. "A Semantics Analysis of First-Year Physics Teaching: Developing Students' Use of Representations in Problem-Solving”. In Building Knowledge in Higher Education: Enhancing Teaching and Learning with Legitimation Code Theory, edited by C. Winberg, S. McKenna and K. Wilmot, 162-79. London: Routledge. https://doi.org/10.4324/9781003028215.

De Freitas, E., and N. Sinclair. 2012. "Diagram, Gesture, Agency: Theorizing Embodiment in the Mathematics Classroom". Educational Studies in Mathematics 80: 133-52. https://doi.org/10.1007/s10649-011-9364-8.

De Freitas, E., and N. Sinclair. 2014. Mathematics and the Body: Material Entanglements in the Classroom. Cambridge: Cambridge University Press. https://doi.org/10.1017/CBO9781139600378.

Deleuze, G., and F. Guattari. 1987. A Thousand Plateaus: Capitalism and Schizophrenia. Minneapolis, MN: University of Minnesota Press.

Dufresne, R. J., W. J. Gerace, and W. J. Leonard 1997. "Solving Physics Problems with Multiple Representations”. The Physics Teacher 35: 270-75. https://doi.org/10.1119/1.2344681.

Fredlund, T., J. Airey, and C. Linder. 2012. "Exploring the Role of Physics Representations: An Illustrative Example from Students Sharing Knowledge about Refraction". European Journal of Physics 33 (3): 657-66. https://doi.org/10.1088/0143-0807/33/3/657. 
Haraway, D. 2008. When Species Meet. Minneapolis, MN: University of Minnesota Press.

Harfouch, J. 2018. Another Mind-Body Problem: The History of Racial Non-Being. Albany, NY: State University of New York Press.

Hwang, S., and W.-M. Roth. 2011. Scientific and Mathematical Bodies: The Interface of Culture and Mind. Rotterdam: Sense Publishers. https://doi.org/10.1007/978-94-6091-5673.

Jansen, J., ed. 2019. Decolonisation in Universities: The Politics of Knowledge. Johannesburg: Wits University Press. https://doi.org/10.18772/22019083351.

Kohl, P. B., and N. D. Finkelstein. 2008. "Patterns of Multiple Representation Use by Experts and Novices During Physics Problem Solving". Physical Review Special Topics: Physics Education Research 4 (1): 010111. https://doi.org/10.1103/PhysRevSTPER.4.010111.

Kress, G., C. Jewitt, J. Ogborn, and C. Tsatsarelis. 2001. Multimodal Teaching and Learning: The Rhetorics of the Science Classroom. London: Continuum.

Lakoff, G., and R. E. Núñez. 2000. Where Mathematics Comes from: How the Embodied Mind Brings Mathematics into Being. New York, NY: Basic Books.

Lemke, J. 1990. Talking Science: Language, Learning and Values. Norwood, NJ: Ablex Publishing.

Ma, X. 1999. “A Meta-Analysis of the Relationship Between Anxiety towards Mathematics and Achievement in Mathematics". Journal for Research in Mathematics Education 30 (5): 520-41. https://doi.org/10.2307/749772.

Martin, J. 2007. “Construing Knowledge: A Functional Linguistic Perspective.” In Language, Knowledge and Pedagogy: Functional Linguistic and Sociological Perspectives, edited by F. Christie and J. Martin, 34-64. London: Continuum.

Moje, E. B. 2007. "Developing Socially Just Subject-Matter Instruction: A Review of the Literature on Disciplinary Literacy Teaching". Review of Research in Education 31 (1): 144. https://doi.org/10.3102/0091732X07300046001.

Newfield, D. 2014. “Transformation, Transduction and the Transmodal Moment”. In The Routledge Handbook of Multimodal Analysis, 2nd ed., edited by C. Jewitt, 100-14. London: Routledge.

OECD (Organisation for Economic Co-operation and Development). 2008. Encouraging Student Interest in Science and Technology Studies. Paris: OECD. https://doi.org/10.1787/9789264040892-en.

O’Halloran, K. 2005. Mathematical Discourse: Language, Symbolism and Visual Images. London: Continuum. 
Rotman, B. 2014. Foreword to Mathematics and the Body: Material Entanglements in the Classroom, by E. De Freitas and N. Sinclair, xiii-xviii. Cambridge: Cambridge University Press.

Rosengrant, D., A. van Heuvelen, and E. Etkina. 2009. "Do Students Use and Understand FreeBody Diagrams?" Physical Review Special Topics: Physics Education Research 5: 010108. https://doi.org/10.1103/PhysRevSTPER.5.010108.

Sfard, A. 2008. Thinking as Communicating: Human Development, the Growth of Discourses, and Mathematizing. Cambridge: Cambridge University Press. https://doi.org/10.1017/CBO9780511499944.

Sinclair, N., and S. Gol Tabaghi. 2010. "Drawing Space: Mathematicians' Kinetic Conceptions of Eigenvectors". Educational Studies in Mathematics 74: 223-40. https://doi.org/10.1007/s10649-010-9235-8.

Van Heuvelen, A. 1991. "Learning to Think Like a Physicist: A Review of Research-Based Instructional Strategies”. American Journal of Physics 59 (10): 891-97. https://doi.org/10.1119/1.16667.

Volkwyn, T. S., J. Airey, B. Gregorcic, F. Heijkensköld, and C. J. Linder. 2017. "Physics Students Learning about Abstract Mathematical Tools When Engaging with 'Invisible' Phenomena". In 2017 PERC Proceedings, edited by L. Ding, A. L. Traxler and Y. Cao, 408-11. College Park, MD: American Association of Physics Teachers. https://doi.org/10.1119/perc.2017.pr.097.

Volkwyn, T. S., J. Airey, B. Gregorcic, and F. Heijkenskjöld. 2019. "Transduction and Science Learning: Multimodality in the Physics Laboratory”. Designs for Learning 11 (1): 16-29. https://doi.org/10.16993/dfl.118. 